\title{
Size Structure and Gonad Characterization of Gari elongata (Lamarck 1818) from the Coastal Areas of Hinatuan, Surigao Del Sur, Philippines
}

\author{
Exur M. Buenaflor ${ }^{1, a^{*}}$, Romell A. Seronay ${ }^{1,2, b}$ and Joycelyn C. Jumawan ${ }^{1, c}$ \\ 1Department of Biology, Caraga State University, Ampayon, Butuan City, Philippines \\ ${ }^{2}$ Department of Environmental Sciences, Caraga State University, Ampayon, Butuan City, \\ Philippines
}

aruxe05@gmail.com*, bromell.seronay@gmail.com, cjoycejumawan1981@gmail.com

Keywords: Gari elongata, Gonad histology, LWR, Hinatuan Surigao del Sur

\begin{abstract}
Size-structure analyses and gonad characteristics of the elongate sunset clam Gari elongata from the coastal waters of Hinatuan, Surigao del Sur, Philippines, was determined in this study. An opportunistic sampling approach was applied during the collection of G. elongata from the coastal waters of Brgy. Loyola and Brgy. Aquino. A total of 1437 G. elongata individuals were subjected to length-weight measurements, and gonads from five (5) individuals per sex among size classes were processed for histological characterization. The maximum total length of G. elongata recorded is $5.42 \mathrm{~cm}$, way smaller than its congeners elsewhere, which is at 7.0-9.2 cm. The sizestructure analysis shows that $G$. elongata from Brgy. Loyola exhibited negative allometric growth while those gleaned from Brgy. Aquino exhibited positive allometry indicating variation in growth dynamics. Known as a gleaning source, Barangay Loyola is abundant in G. elongata, but individuals are much smaller compared to those gathered from Barangay Aquino. A ratio of 1:1 for male and female classification was observed, as seen from gonad histological analyses. Ovaries were found in the spawning capable state with gonads in ripe $(30 \%)$, spent $(25 \%)$, early development $(25 \%)$, and partially spawning $(20 \%)$ stages. Testes were found to be in the ripe (40\%), early developing (10\%), spent (10\%), and partially spawning (40\%) stages. Gari elongata exhibits spawning capable gonads at $2.85 \mathrm{~cm}$ and $2.95 \mathrm{~cm}$ for males and females, respectively, which suggests that the shellfish has adapted early to reproduction to maintain its population in the coastal waters of Hinatuan. The small body lengths of individuals with mature gonads indicate that $G$. elongata may have been exposed to some stress in their natural environment. Regulated management of $G$. elongata to avoid over-harvesting and assessment of water and sediment quality of their natural habitat is highly recommended
\end{abstract}

\section{Introduction}

Bivalves of the family Psammobiidae commonly dominate exposed intertidal sandy beaches constituted by the genera Gari and Psammotaea [1]. The elongate sunset clam G. elongata (Lamarck 1818) is known to be a deposit or suspension-consuming bivalves, lying repressed at an oblique angle to the surface. This species is fast-growing; however, short-lived, which is typical for tropical species [2]. Gari elongata is a dioecious species, but in a few specimens, hermaphroditism was observed [3]. This species has been shown to have marine ancestry and has been able to acclimatize to a freshwater habitat; it has a fast growth rate and has the potential as a biofilter in fresh - to brackish water polycultures [2]. Gari elongata is exploited for bait, and their unique, delicate taste makes them a potentially valuable food resource.

Hinatuan, Surigao del Sur is located in the north-eastern part of Mindanao Island facing the Pacific Ocean in the east. It is surrounded by the Municipalities of Tagbina in the west, Barobo in the north, and the City of Bislig in the south. Half of the population lives along the coast; of these, roughly 1560 are fisher folks [4]. In the coastal waters of Hinatuan, G. elongata, locally known as "balisaa," is popularly gleaned, however, without known regulations. Despite their potential value, many aspects of their population dynamics (reproduction, growth, production, mortality) in the coastal waters of Hinatuan, Surigao del Sur, are still unknown. 
Knowledge of $G$. elongata population dynamics is essential for the understanding of its ecology and crucial to support future aquaculture, exploitation activities, and management. Moreover, a description of the reproductive status of this bivalve is a vital baseline to help interpret its growth pattern and population biology as well as help ensure a steady supply of broodstock and fertilizable eggs [2]. The main objective of this study is to determine the length and weight relationships (LWR) of and histologically examine the gonad stages of $G$. elongata from the coastal waters of Hinatuan.

\section{Materials and Methods}

\section{Description of Study Area}

Two coastal barangays in Hinatuan were selected as sampling stations for G. elongata (Figure 1). The study area in Brgy Loyola is brackish and near the river mouths of Tagasaca River and Loyola River. The location has very few houses, but it is a popular gleaning area for G. elongata, among other fishery resources. Brgy Aquino is located near the mouth of Hinatuan River, wherein commercial establishments and numerous houses surrounded the area. This location is not a known area for gleaning; however, G. elongata populations are observed.

\section{Collection of and sorting of G. elongata}

Simultaneous collection of bivalve samples was done in the two barangays on January 27, 2018, during low tide. An opportunistic sampling approach was applied during the collection of the shellfish samples with approximately 3 hours spent for collection in each study area. All class sizes of $G$. elongata were randomly gleaned from the area. The collected samples were stored in net bags with marks corresponding to the site where samples were collected, and transported to the laboratory. The length and weight measurements were obtained from all collected individuals regardless of sex due to the absence of external sexual dimorphism in this species. A vernier caliper was used to obtain the total length (TL in $\mathrm{cm}$ ) to the nearest $0.01 \mathrm{~mm}$. The total length (TL), Total weight (TW in $\mathrm{g}$ ), and gonad weight ( $\mathrm{GW}$ in $\mathrm{g}$ ) of each individual were taken to the nearest $0.01 \mathrm{~g}$ using a digital electronic balance. The bivalves were categorized into six size classes: $1.0-2.55 \mathrm{~cm}$; 2.56-3.25 cm; 3.26-3.95 cm; 3.96-4.65 cm; 4.66-5.35 cm and 5.36- and above.

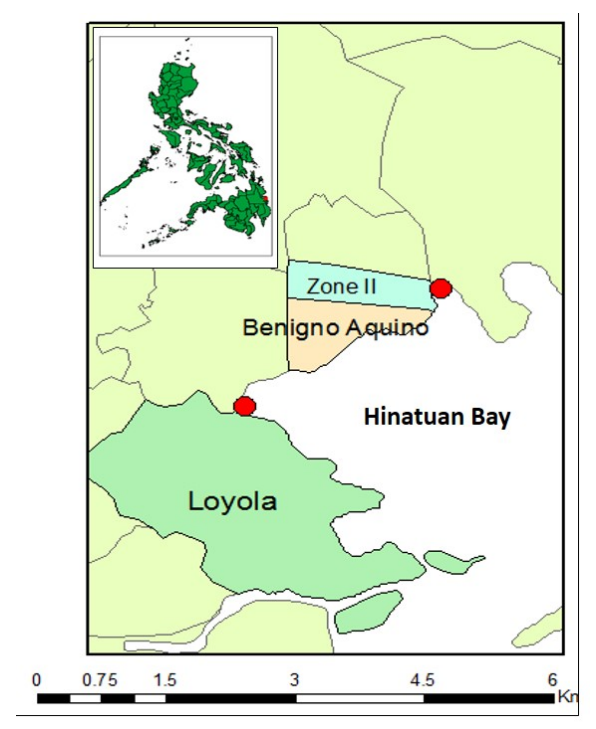

Figure 1. Collection stations (red circles) of G. elongata in the coastal areas of Hinatuan, Surigao del Sur, Philippines

Length-Weight Relationship (LWR)

The length-weight relationships (LWR) of G. elongata individuals was determined following the equation $\mathrm{W}=\mathrm{aL}^{\mathrm{b}}$, where $\mathrm{W}$ is the total body weight, ' $\mathrm{a}$ ' as the regression intercept, ' $\mathrm{L}$ ' as the 
average length and ' $b$ ' as the regression coefficient $[5,6]$. The limits $a, b$, and $r^{2}$ (coefficient of determination) were assessed by least squares regression inquiry of the logarithm-transformed LWR illustration $\log \mathrm{W}=\mathrm{b} \log \mathrm{L}+\log$ a with "W" as the dependent variable. The 'b' is an exponent with estimation between 2.5 and 3.5 to illustrate standard growth dimensions of comparative well-being [7]. Analysis of covariance (ANCOVA) and was used to compare size structure characteristics between stations.

Preparation of the Shellfish Samples for Histology Analysis

Individuals from the two study stations were randomly sampled from the six size classes. The middle portion of the gonads was dissected and used for histological processing. Gonads were preserved in Bouin's solution for 24 hours at room temperature. Organs were rinsed with tap water and were transferred to $70 \% \mathrm{ETOH}$ for storage. Tissues were sent to the Philippine Kidney Dialysis Foundation (PKDF), Roces Ave., Quezon City for standard histological procedures with Hematoxylin and Eosin (H\&E) staining [8]. The prepared slide samples were examined using a light microscope. Gonads were assigned to one of the five developmental stages, following the stages described by Nabuab and Del Norte-Campos [3]. The sexes of individuals were determined from prepared slides under light microscopy. Size at sexual maturity was determined based on the shell individual with the smallest TL with a ripe or mature gonad from prepared slides.

\section{Results}

\section{Length Frequency Distribution}

A total of 1437 G. elongata individuals were collected from the two study stations with 803 and 634 individuals from Brgy Loyola and Brgy Aquino, respectively. The maximum TL of $G$. elongata was $5.45 \mathrm{~cm}$, while the smallest TL was recorded at $1.8 \mathrm{~cm}$ (Table 1). The maximum weight observed was 10.92 g. Gari elongata from Brgy. Aquino has larger sizes than those from Brgy. Loyola, but the latter has more individuals collected than the former. Smaller sized $(1.85-3.95 \mathrm{~cm}) \quad G$. elongata are abundant in Brgy Loyola while in the bigger sizes $(3.96 \mathrm{~cm}-$ onwards) can be seen in Brgy Aquino (Figure 2,3). The LWR parameters are described in Table 1 and Figure 3. The growth dimensions (b) of G. elongata from the two stations differ with Brgy. Loyola being negatively allometric $(<3.0)$, while those from Brgy Aquino are positively allometric $(>3.0)$. All slopes in the regressions between study areas were found to be highly significant $(\mathrm{p}<0.01)$ with the following equations derived: Loyola: $\mathrm{TW}=-4.502(\mathrm{TL})^{2.31} \mathrm{r}^{2}=0.90 ; \mathrm{n}=803$ and Aquino: $\mathrm{W}=-8.29$ (TL) ${ }^{3.39} \mathrm{r}^{2}=0.91 ; \mathrm{n}=634$.

Table 1. Length-weight relationships in G. elongata from two coastal areas of Hinatuan Bay

\begin{tabular}{|c|c|c|c|c|c|c|}
\hline Area & $\mathbf{N}$ & b $(95 \% \mathrm{Cl})$ & a $(95 \% \mathrm{Cl})$ & $\mathbf{R}^{2}$ & TL & BW \\
\hline $\begin{array}{c}\text { Station } 1 \\
\text { (Brgy. } \\
\text { Loyola) }\end{array}$ & 803 & $\begin{array}{c}2.31 \\
(2.23-2.39)\end{array}$ & $\begin{array}{c}-4.50 \\
(-4.77-4.23)\end{array}$ & 0.90 & $\begin{array}{c}3.43 \\
(1.80-5.08)\end{array}$ & $\begin{array}{c}3.40 \\
(0.66-10.92)\end{array}$ \\
\hline $\begin{array}{c}\text { Station } 2 \\
\text { (Brgy. } \\
\text { Aquino) }\end{array}$ & 634 & $\begin{array}{c}3.39 \\
(3.26-3.51)\end{array}$ & $\begin{array}{c}-8.30 \\
(-8.80-7.80)\end{array}$ & 0.91 & $\begin{array}{c}3.98 \\
(2.52-5.45)\end{array}$ & $\begin{array}{c}5.20 \\
(1.15-10.79)\end{array}$ \\
\hline Pooled & 1437 & $\begin{array}{c}2.77 \\
(2.23-3.51)\end{array}$ & $\begin{array}{c}5.98 \\
(-4.77-7.80)\end{array}$ & 0.91 & $\begin{array}{c}3.69 \\
(1.80-5.45)\end{array}$ & $\begin{array}{c}4.20 \\
(0.66-10.92)\end{array}$ \\
\hline
\end{tabular}




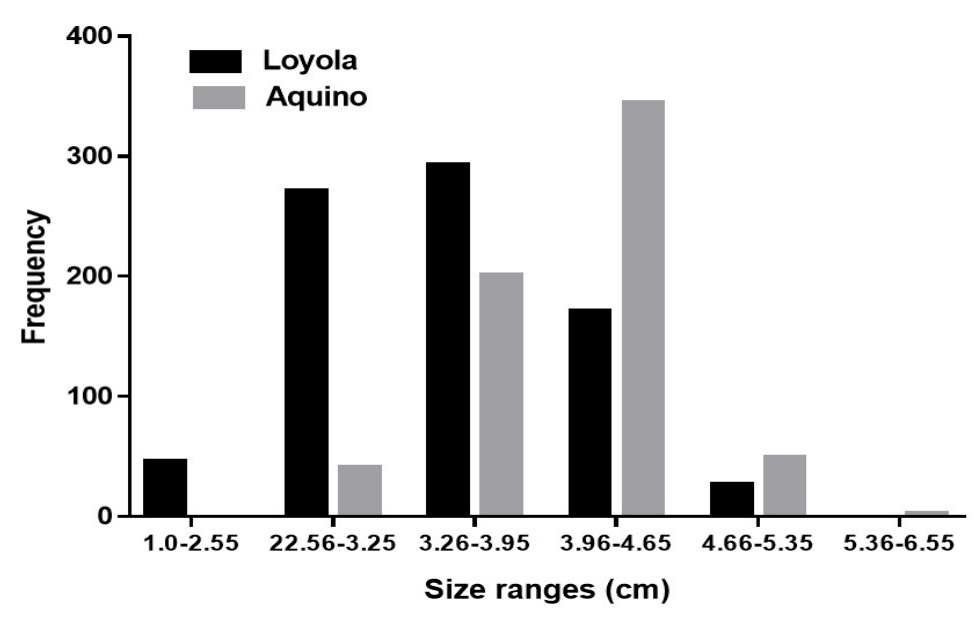

Figure 2. Frequency distribution of G. elongata from Hinatuan Bay among size classes

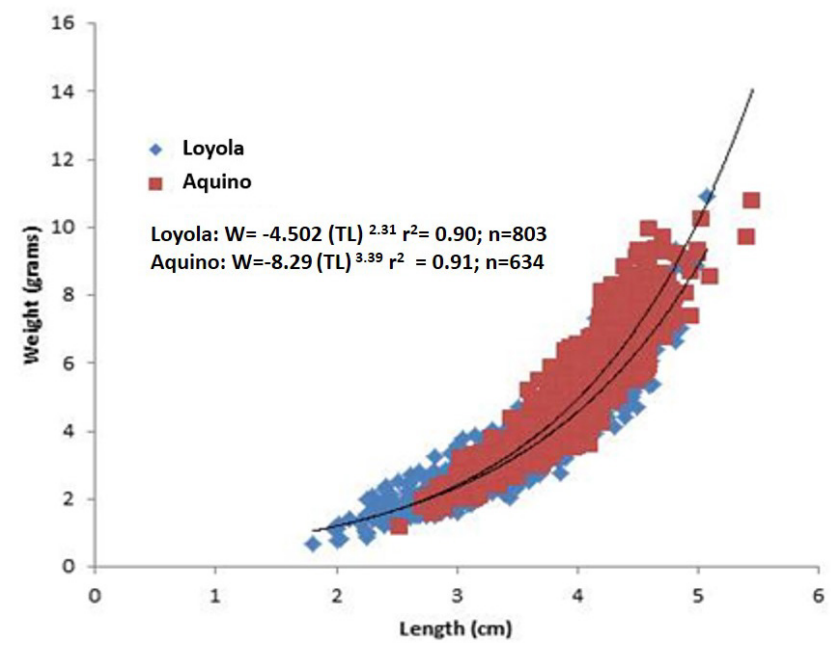

Figure 3. Length-weight relationships of G. elongata from the two coastal areas of Hinatuan Bay

Gonad activity in $G$. elongata

The gonads are of G. elongata creamy white, regardless of the stage of maturity. It was not possible to evaluate the gonadal maturity of the individuals based on the external appearance of the testis and ovary; hence, the need for histological assessment. Gonad maturity of G. elongata was characterized to assess the gonad activity based on shell length. Among randomly sampled gonads across the six size classes, a ratio of 1:1 in male to female classification was observed. Based on histological staging, ovaries of $G$. elongata were observed to be in ripe (30\%), spent (25\%), early development (25\%), and partially spawning (20\%) stages (Figure 4). The smallest female $G$. elongata exhibiting a spawning-capable stage was observed at $2.95 \mathrm{~cm}$. Testes assessed histologically across size classes exhibited similar stages with the female gonads where testis exhibited ripe (40\%), early developing (10\%), spent $(10 \%)$, and partially spawning $(40 \%)$ stages (Figure 5).

\section{Discussion}

The allometry in the shell width and weight relationships of $G$. elongata could be explained by the generally elongated (oval) and depressed (thin) shape that most bivalves attain [9]. Growth along the three-dimensional axes is non-uniform, with the horizontal being faster than the vertical and lateral dimensions [2]. The largest TL recorded for G. elongata from the coastal areas of Hinatuan at $5.45 \mathrm{~cm}$ is relatively small compared to the earlier records of Del-Norte Campos [2] in Banate Bay, an unexploited area in Western Visayas at $9.2 \mathrm{~cm}$. Willan [1] reported that the 
maximum shell length of $G$. elongata is $7.0 \mathrm{~cm}$ and commonly $5.5 \mathrm{~cm}$. The maximum length reported in the present study $(5.45 \mathrm{~cm})$ could most probably be due to overharvesting or over gleaning, a scenario that was actively observed in Brgy. Loyola. Significant differences in the growth dimensions of $G$. elongata were also seen in the two study areas, with specimens from Brgy. Loyola being smaller-sized compared to those from Brgy. Aquino, which are significantly bigger. Differences in allometry have been shown in many studies as an indication of overharvesting and exploitation $[10,11,12]$.
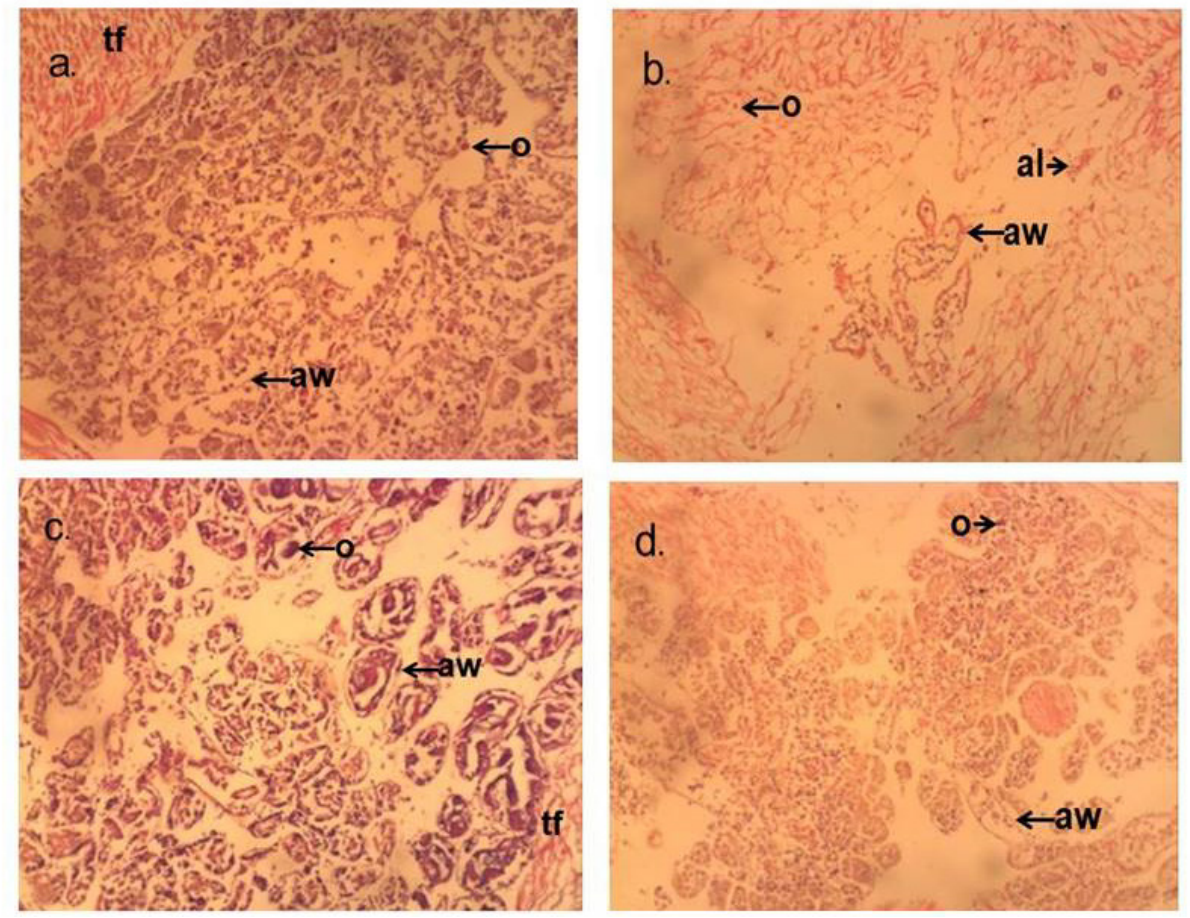

Figure 4. Some representative sections of G. elongata ovaries. (a) ripe; (b) spent; (c) partially spawned; (d) developing. Abbreviations: $a w=$ alveolar wall; $t f=$ transverse fiber; $a l=$ alveolus; $\mathrm{o}=$ oocytes. LPO
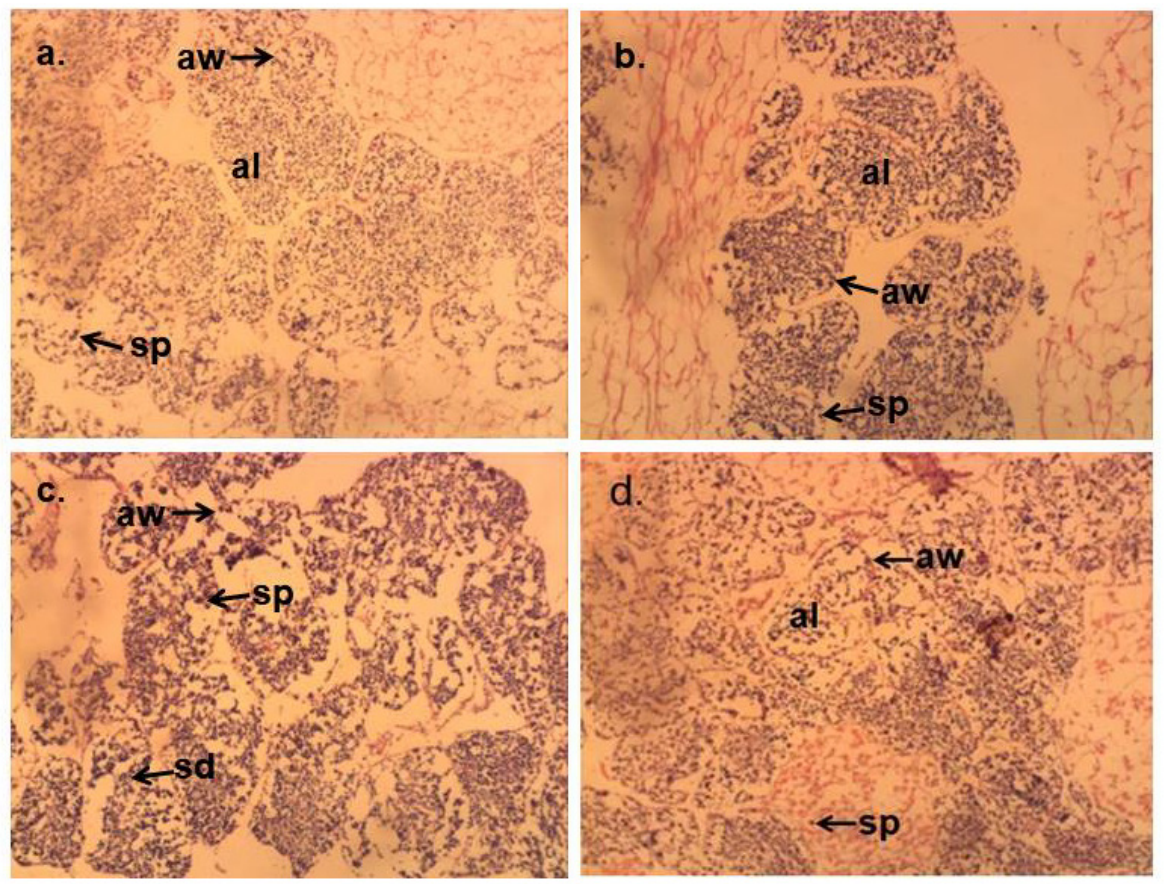

Figure 5. Some representative sections of G. elongata testis. (a) early development; (b) ripe;

(c) partially spawned; (d) spent. Abbreviations: aw = alveolar wall; al = alveolus; $\mathrm{sp}=$ spermatozoa; $\mathrm{sd}=$ spermatids 
Externally, G. elongata cannot be distinguished as male or female, exhibiting no sexual dimorphism. While G. elongata is known as a dioecious species, hermaphrodism can be observed in some individuals [2]. Del Norte-Campos [3] has indicated that G. elongata from Banate Bay, West Central Philippines exhibit most active gonad maturity with shell widths $>40 \mathrm{~mm}$, which could serve as the minimum harvest size that a fishery should allow ensuring the viability of future recruits. In the current study, smaller-sized G. elongata were shown to exhibit spawning-capable gonads indicating possible plasticity in response to exploitation and overharvesting [13].

Salinity, nutrients, pollution, and seasonal reproduction can be a factor in size and gonad maturity. Gari elongata is known to reproduce throughout the year [2, 3]. However, a major and a minor spawning peak occurring between December-January and May-June are observed. These two spawning peaks may most likely be influenced by the monsoons which in turn, affect the precipitation and salinity levels in the species' habitat. [2]. Tributaries and the waters that converge in the two study stations can influence the dynamics of growth aside from the utilization of this bivalve resource. Waters that empty to Hinatuan Bay are threatened with different sources of pollution from mining, domestic, agriculture, and tourism [14]. It has been proven that biochemical indicators provide more precise information about gonad operation and environmental pressure [15]. Further assessment and annual monitoring of bio-physicochemical parameters that can potentially impact the dynamics and reproduction of G. elongata is recommended.

\section{Conclusions}

The elongate sunset clam G. elongata from the coastal waters of Hinatuan, Surigao del Sur, Philippines, was studied in terms of size structure relationships and gonad stages. Results indicate that there is a difference in allometric growth between study stations Brgy. Loyola - a known gleaning area for $G$. elongata and Brgy Aquino, where G. elongata is underutilized, indicating variation in growth dynamics. Differences in sizes and abundance of $G$. elongata may indicate disturbance, overexploitation of this resource. Histological assessment of the gonads also indicates that $G$. elongata from the coastal areas of Hinatuan Bay undergo spawning-capable gonads at smaller sizes compared to their congeners, as reported from other studies. It is highly recommended that the growth dynamics of this bivalve resource be monitored annually along with the assessment of the possible influence of salinity and nutrient gradients and pollution to provide defined management strategies to conserve G. elongata.

\section{Conflict of Interest}

The authors declare no conflict of interest.

\section{Acknowledgments}

The authors would like to thank the Aquatic Biology Laboratory of the Department of Biology, Caraga State University, and MSU- Naawan, Integrated Research, and Fisheries Development (IRFD) for the use of the equipment and species identification of our samples. 


\section{References}

[1] R.C. Willan. Taxonomic revision of the family Psammobiidae (Bivalvia: Tellinoidea) in the Australian and New Zealand Region. Records of the Australian Museum Supply, 18 (1993), $1-132$.

[2] A. G. C. Del Norte-Campos. Some aspects of the population biology of the sunset elongate clam Gari elongata (Lamarck 1818) (Mollusca, Pelecypoda: Psammobiidae) from the Banate Bay Area, West Central Philippines. Asian Fisheries Science, 17 (2004), 299-312.

[3] F. M. Nabuab, A. del Norte-Campos. Some aspects of the reproduction in the elongate sunset clam, Gari (Gabraeus) elongata (Lamarck 1818) from Banate Bay Area, West Central Philippines. Science Diliman, 18.2 (2006).

[4] R. Byrne, E. Hines. The marine turtles of Hinatuan Bay, Surigao del Sur, Mindanao, Philippines. Marine Turtle Newsletter, 107, 8 (2005).

[5] H.J. Urban, B. Campos. Population dynamics of the bivalves Gari solida, Semele solida and Protothaca thaca from a small bay in Chile at $36^{0} \mathrm{~S}$. Marine Ecology-Progress Series, 115 , (1994), 93-93.

[6] H.J. Urban. Culture potential of the pearl oyster (Pinctada imbricata) from the Caribbean.: I. Gametogenic activity, growth, mortality and production of a natural population. Aquaculture, 189 (2000), 361-373.

[7] P. Vasconcelos, P. Moura, F. Pereira, A.M. Pereira, M.B. Gaspar. Morphometric relationships and relative growth of 20 uncommon bivalve species from the Algarve coast (southern Portugal). Journal of the Marine Biological Association of the United Kingdom, 98 (2018), 463-474.

[8] Y. Kim, K.A. Ashton-Alcox, E.N. Powell. Histological Techniques for Marine Bivalve Molluscs: Update. Silver Spring, MD. NOAA Technical Memorandum NOS NCCOS (2006) $27.76 \mathrm{pp}$.

[9] K.S. Cummings, D.L. Graf. Mollusca: Bivalvia. In Ecology and classification of North American freshwater invertebrates . Academic Press (2010) 309-384 pp.

[10] F. A. Argente, J. S. Estacion. 2014. Effect of different harvesting practices on the dynamics of Paphia textile (Gmelin 1792)(Bivalvia: Veneridae) populations at two sites in Zamboanga del Norte, Southern Philippines. Environmental and Experimental Biology, 12 (2014), 113-120.

[11] S. Çolakoğlu, M. Palaz, Some population parameters of Ruditapes philippinarum (Bivalvia, Veneridae) on the southern coast of the Marmara Sea, Turkey. Helgol Marine Research, 68 (2014), 539-548.

[12] J. Kryger, H. U. Riisgård. Filtration rate capacities in 6 species of European freshwater bivalves. Oecologia, 77 (1988), 34-38.

[13] F. Ghribi, G. Bello, R. Zupa, L. Passantino, N. Santamaria, M. E. Cafsi, A. Corriero. Reproductive and tissue plasticity in Arca noae (Bivalvia: Arcidae). The European Zoological Journal, 84 (2017), 473-487.

[14] C. A. Vera, R. Cabaces, L. Reyes. Asserting Rights, Defining Responsibilities Perspectives from Small-Scale fishing Communities on Coastal and Fisheries Management in the Philippines, International Collective in Support of Fishworkers, 978 (2007), 44-60.

[15] R. Smolders, M. Baillieul, R. Blust. Relationship between the energy status of Daphnia magna and its sensitivity to environmental stress. Aquatic Toxicology, 73 (2005), 155-170. 